\title{
Why are long-acting beta-adrenoceptor agonists long-acting?
}

\author{
G.P. Anderson*, A. Lindén**, K.F. Rabe†
}

\begin{abstract}
Why are long-acting beta-adrenoceptor agonists long-acting?. G.P. Anderson, A. Lindén, K.F. Rabe. CERS Journals Ltd 1994.

ABSTRACT: The extended duration of bronchodilation due to formoterol and

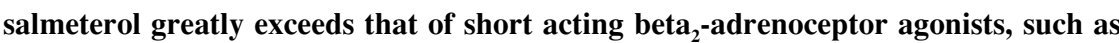
salbutamol or terbutaline. This extended duration and their capacity to "reassert" airway smooth muscle relaxation in vitro despite repeated washing has prompted considerable debate on the underlying mechanism(s). The comparative pharmacology, and molecular modelling of these drugs and of the beta ${ }_{2}$-adrenoceptor and its ligand binding core have cast doubt on the exosite/exoceptor model previously proposed to explain the behaviour of salmeterol.

We present evidence supporting a unifying hypothesis that the duration of action both of formoterol and salmeterol is determined principally by their physicochemical interactions with membrane lipid bilayers (plasmalemma diffusion microkinetic model), rather than putative distinct exosite/exoceptor binding sites in or near the beta $_{2}$-adrenoceptor. This model provides a clearer understanding of the pharmacological profile of these drugs (rate of onset, duration, "reassertion", interaction with hydrophilic and hydrophobic beta $_{2}$-adrenoceptor antagonists), and explains why in human airway smooth muscle in vitro a true relaxation-concentration response may not exist for salmeterol.

Eur Respir J., 1994, 7, 569-578.
\end{abstract}

\author{
*Research Dept, Ciba-Geigy AG, Basel, \\ Switzerland. **Division of Pulmonary Medi- \\ cine, University of Göteborg, Renströmska \\ Hospital, Göteborg, Sweden. †Krankenhaus \\ Grosshansdorf, Zentrum für Pneumologie \\ und Thorax Chirurgie, LVA Hamburg, \\ Grosshansdorf, Germany. \\ Correspondence: G.P. Anderson \\ Research Dept \\ R1056.2.17 \\ Ciba-Geigy AG \\ CH 4002, Basal \\ Switzerland \\ Keywords: Airway smooth muscle \\ bronchodilator \\ exosite \\ formoterol \\ membrane diffusion \\ salmeterol
}

Received: February 121993

Accepted after revision October 31993

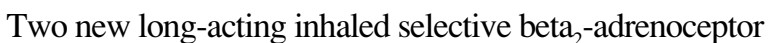
agonists, formoterol and salmeterol, have recently become available for the treatment of reversible airflow obstruction in asthma. Extensive clinical trial data have been obtained with these drugs, which indicate that they both cause significant bronchodilation for at least $12 \mathrm{~h}$ after a single administration [1-5]. Both compounds are well-tolerated and highly potent; the principal difference in their clinical pharmacology being the faster onset of action of formoterol compared to salmeterol [6-8]. The extended duration of action of formoterol and salmeterol, which greatly exceeds that of more familiar beta ${ }_{2}$-adrenoceptor agonists, such as salbutamol and terbutaline, has prompted considerable debate on the underlying mechanism(s). This review describes the evidence supporting a unifying hypothesis that the duration of action of both formoterol and salmeterol is determined principally by their physicochemical interactions with membrane lipid bilayers, rather than putative exoceptor binding sites in or near the beta ${ }_{2}^{-}$ adrenoceptor.

\section{Pharmacological and physicochemical properties of formoterol and salmeterol}

The basic pharmacological properties of formoterol and salmeterol are somewhat similar. Both drugs are highly potent relaxants of human bronchial smooth muscle in vitro (negative $\log _{10}$ molar concentration for half maximal relaxation \pm SEM: formoterol $9.6 \pm 0.1$; salmeterol 7.6 \pm 0.2 ; potency ratio 107 at basal tone) [9]. In addition, they both display a high degree of selectivity for the beta $_{2}$-adrenoceptor subtype [10-13]. The important differences observed in vitro are that formoterol has a higher intrinsic efficacy $[9,12,14]$ and a faster onset of relaxation than salmeterol [15]. The dissociation constant, $-\log _{10} \mathrm{KD}$, is a measure of affinity of drugs for receptors. Formoterol has a very high binding affinity for the beta adrenoceptor, with a $-\log _{10} \mathrm{KD}=8.12$ for displacement of ICI 118,551 , a selective beta ${ }_{2}$-adrenoceptor antagonist, versus 6.44 for salbutamol [12]. The apparent binding affinity of salmeterol is also relatively high $\left(-\log _{10} \mathrm{KD}\right.$ salmeterol 7.82) and greater than that of salbutamol ($\log _{10} \mathrm{KD}_{\mathrm{D}} 5.63$ ) for displacement of ${ }^{125}$ iodine-labelled pindolol from guinea-pig lung tissues [16].

The structures of formoterol, a formanilide substituted phenoethanolamine, and salmeterol, a saligenin derivative of phenylethanolamine, are shown in figure 1. Computerassisted molecular modelling (CAMM) studies predict that formoterol is approximately $13-15 \AA$ long in aqueous solution in its lowest energy conformations. Despite the apparently lengthy aliphatic side-chain attached to its saligenin head group, salmeterol is predicted to be less than twice the length of formoterol $(25 \AA)$ (CAMM 
<smiles>COc1ccc(CC(C)NCC(O)c2ccc(O)c(NC=O)c2)cc1</smiles><smiles>OCc1cc(C(O)CNCCCCCCCCCCCCCCc2ccccc2)ccc1O</smiles>

Fig. 1. Chemical structures of formoterol and salmeterol. Formoterol is a pure diasteriomer comprising an exact 1:1 mixture of the (RR) and (SS) enantiomers of 2-hydroxy-5-[(1RS)-hydroxy-2-(p-methoxyphenyl)-1-methylethyl]amino] ethyl] formanilide formulated as the fumerate dihydrate salt. Salmeterol is a pure racemate comprising an exact 1:1 mixture of the (R) and (S) enantiomers of (4-hydroxy-alpha-[6-[4phenylbutyl)oxy]hexyl]amino]methyl]-1,3-benzenedimethanol formulated as the xinofoate or hydroxynaphthoate salts.

studies were kindly performed by N. Cohen (Ciba-Geigy, Basel, Switzerland), using the "MacroModel" Modelling System analysis software supported on a VAX mainframe computer [17]. The side-chain does, however, profoundly affect the lipophilicity of salmeterol, which is at least an order of magnitude more lipid soluble than the moderately lipophilic formoterol molecule: the octanol-to-water partition coefficients are: formoterol $=2.6$ and salmeterol $=63$ at $\mathrm{pH} 7.4$ [15]. As argued below, it is the physicochemical nature of the interactions of formoterol or salmeterol with the membrane lipid bilayer that may determine the duration of action and other behaviours of these molecules in vitro and in vivo. It should be stressed at this point that lipophilicity (octanol:water partition) and membrane lipid bilayer affinity $\left(\mathrm{Kp}_{(\mathrm{mem})}\right)$ are by no means identical, and the octanol:water partition coefficient is only a crude predictor of the true extent of drug interactions with biological membranes [18-20].

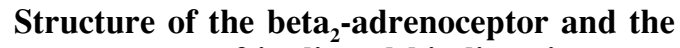 nature of its ligand binding site}

Definitive 3-D X-ray crystallography studies of beta ${ }_{2}$ adrenoceptor or of agonist-receptor complexes have not yet been made. However, a number of indirect methods based on the primary amino acid sequence, such as molecular modelling and hydropathy analysis, and direct epitope mapping of the beta 2 -adrenoceptor using monoclonal antibodies, support the concept that the beta ${ }_{2}$-adrenoceptor is composed of seven transmembrane spanning sequences arranged in alpha-helices. These helices cluster together, forming a binding clef or active site accessible to ligands approaching through the extracellular aqueous biophase [21-24].

The structure of the beta-adrenoceptor is thought to be an analogue of bacteriorhodopsin, the only protein of this structural class for which definitive 3-D structural information has been obtained $[25,26]$, and the mammalian G-protein-coupled visual pigment rhodopsin [27, 28]. The dimensions of bacteriorhodopsin are known to be $25 \times 35 \AA$ in the plane of the lipid membrane bilayer and
$45 \AA$ in depth spanning both sides of the bilayer [25]. LEWELL [29] has calculated the dimensions of the beta $2^{-}$ adrenoceptor to be $18 \times 33 \times 45 \AA$. The peptide backbone of the individual alpha-helices is approximately $5 \AA$ in diameter, and the helices are thought to be separated by approximately $10 \AA$. A schematic structural model of the beta $_{2}$-adrenoceptor, highlighting the agonist and antagonist binding regions, is shown in figure 2 .

A body of evidence supports the concept that beta $2^{-}$ adrenoceptor agonists bind to a hydrophobic pocket or active site located at least $11 \AA$ within the core of beta ${ }_{2}$ adrenoceptor, i.e. approximately $30-40 \%$ into the depth of the receptor $[22,23]$. This location corresponds to the predicted location of several key amino acid residues, aspartate 113, serine 204, serine 207 and phenylalanine 290 , known from molecular biology studies on genetically engineered recombinant point-mutated receptors to be crucial for ligand binding [21-24].

The binding of adrenaline to key amino acid residues in the active site of the beta-adrenoceptor has recently been predicted using computer modelling techniques [24]. Based on the known structure-activity relationships, binding affinity states, selectivity and efficacy, it is possible that formoterol and salmeterol interact with the beta $2_{2}^{-}$ adrenoceptor in a manner in which at least some of the bonds formed between the agonists and their receptor are similar to those formed by adrenaline. If this were the case, salmeterol and formoterol would be expected to interact with (using the nomenclature of HiBERT et al. [24] which numbers amino acids from the predicted start of each alpha-helix rather than from the $\mathrm{N}$ terminus), serine 413 (transmembrane domain 4), a highly conserved residue common to all beta-adrenoceptors. Specificity for the beta ${ }_{2}$-adrenoceptor subtype might be determined by interactions with serines 504 and 507 (i.e. serines 204 and 207, located on transmembrane domain 5).

\section{Reassertion, duration and the "exosite" hypothesis}

An extraordinary property of salmeterol is its capacity to "reassert" relaxation of airway smooth muscle $[10,16$, 
a)

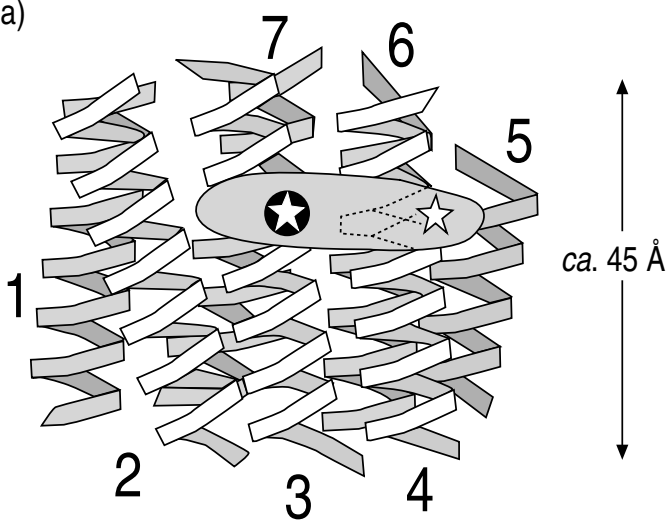

b)

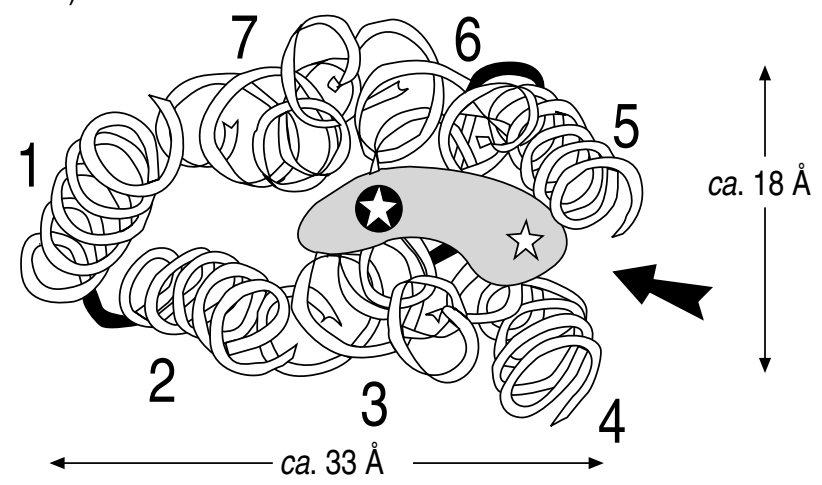

c)

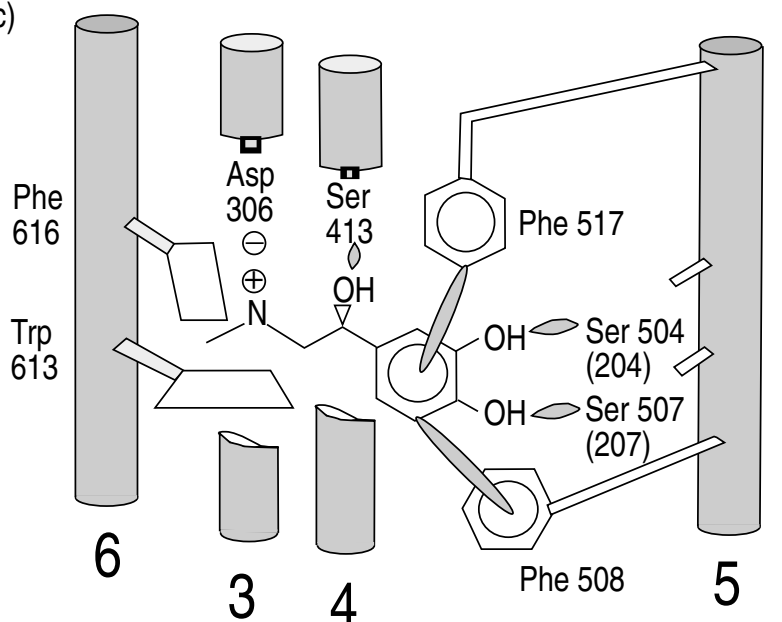

Fig. 2. - Schematic diagram of the beta ${ }_{2}$-adrenoceptor and its binding domains for antagonists and agonists. The ligand core is located

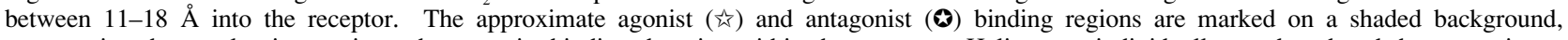
representing the overlap in agonist and antagonist binding domains within the receptor. Helices are individually numbered and the approximate (ca.) dimensions of the receptor are marked in Angstroms ( $\AA$ ) by thin, double-headed arrows. Loops connecting the individual helices have been omitted for clarity. The diagram is not to scale and is adapted from [24, 29]. a) (Side-view) shows a cut-away view of the seven transmembrane alpha-helices of the beta $a_{2}$-adrenoceptor seen from the plane of the membrane lipid bilayer. Ligands approach from the extracellular aqueous biophase (top of panel), signal transduction occurs via G-proteins on the intracellular side (bottom of panel). b) (Top view) shows the same beta ${ }_{2}$-adrenoceptor viewed from the extracellular space. The large arrow marks a possible intercalation site for salmeterol between helices 4 and 5 in the immediate vicinity of the preferential agonist binding region. c) shows an expanded detail of the ligand binding site for agonists formed by helices 3 , 4,5 and 6, during binding of the endogenous catecholamine, adrenaline (norepinephrine). Amino acids are named and numbered according to [24]. Numbers in parentheses (Ser 204, Ser 207) corresponding amino acid numbers in the primary sequence and are given for reference.

30] (fig. 3). This retention of salmeterol in the tissue and "reassertion" is very persistent, since both relaxation and "reassertion" effects have been documented even after 10 complete wash-out cycles or several hours of continuous superfusion of the tissue with drug-free medium [10, 16, 30-34] (fig. 3). This property, which has been held to be unique to salmeterol, has previously been explained in terms of a putative "exosite" or "exoceptor", distinct from the beta ${ }_{2}$-adrenoceptor, which was proposed to bind the pharmacologically inactive long aliphatic tail with high affinity, allowing the active saligenin head structure to angle on and off the receptor in a manner that would allow a beta-adrenoceptor antagonist, such as sotalol, access to the active site of the beta ${ }_{2}$-adrenoceptor (fig. 4) [13, 16, 31].

However, it should be noted that persistent in vitro relaxant activity and the "reassertion" effect, are properties common to several lipophilic beta ${ }_{2}$-adrenoceptor agonists. These effects have previously been reported for clenbuterol; salmefamol, a saligenin derivative of formoterol; and, the experimental compound D2489, the resorcinol analogue of salmeterol $[15,35,36]$. In recent experiments, in which preparations of guinea-pig trachea have been precontracted with carbachol to induce submaximal contraction and then relaxed with sub- or supra-maximal concentrations of salbutamol or formoterol, salbutamol showed virtually no capacity to reassert relaxation after repeated washing of the tissues. In contrast, formoterol produced consistent reassertion of relaxation of $78 \pm 7 \%$ (mean \pm SEM) (fig. 3). Furthermore, in human airway smooth muscle, formoterol protects against acetylcholineinduced contraction, despite repeated washing of the tissue, over a period of more than $6 \mathrm{~h}$ [9].

The capacity of several lipophilic beta-adrenoceptor agonists lacking a long side-chain to behave as if they were interacting with an "exosite" raises fundamental questions about the mechanism of long duration of action for formoterol, and about the validity of the "exosite" 


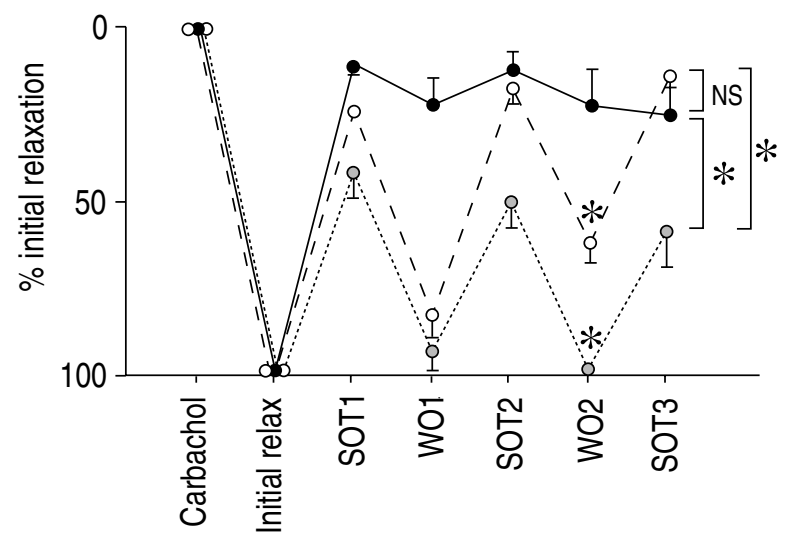

Fig. 3. - Reassertion behaviour of long- but not short-acting beta ${ }_{2}$-adrenoceptor agonists in guinea-pig trachea. Tissues were contracted with carbachol $(0.2 \mu \mathrm{M})$ to induce approximately $70 \%$ of maximal contraction (Carbachol), which was always present during the experiment. Tissues were then relaxed with the indicated loading concentrations of salbutamol, formoterol or salmeterol (Initial relax), which are tenfold higher than the concentration needed to fully relax the tissue. Sotalol $\left(10 \mu \mathrm{mol} \cdot l^{-1}\right)$, a hydrophilic competitive betaadrenoceptor antagonist, completely blocked this relaxant effect and caused the tissues to contract due to the presence of carbachol (SOT1). Hydrophilic sotalol and unbound beta $a_{2}$-adrenoceptor agonists were removed from the organ bath by washing the preparations five times with fresh buffer solution (WO1). After wash-out the initial relaxation effect "reasserted" in formoterol- and salmeterol-, but not salbutamol-pretreated tissues. This reassertion of relaxation could also be demonstrated after identical wash-out cycles (SOT2, WO2, SOT3, WO3). *: statistically significant difference (Student's t-test; Ns: nonsignificant. Four to eight tracheal preparations were included in each treatment group. $\longrightarrow$ : salbutamol $1 \mu \mathrm{M} ;-\mathrm{O}-$ : formoterol $50 \mathrm{nM} ;--\mathrm{O}--$ : salmeterol $1 \mu \mathrm{M}$. From ref [30].

model. Furthermore, an "exoceptor" is not consistent with a recent computer modelling study of the interaction of salmeterol with the beta ${ }_{2}$-adrenoceptor, which predicted that the tail of salmeterol intercollates between the alphahelices inside the beta ${ }_{2}$-adrenoceptor itself [37]. X-ray diffraction and nuclear magnetic resonance (NMR) studies on ligand-receptor complexes will be required to resolve the exosite theory definitively, but it should also be noted that the apparent binding affinity of salmeterol for the beta-adrenoceptor is actually lower than that of formoterol, and formoterol can be slowly washed from airway smooth muscle in vitro (fig. 3) [35], whereas the biological activity of salmeterol persists for periods in excess of $10 \mathrm{~h}[13$, 16, 31, 38]. An alternative explanation of duration of action accommodating all experimental observations is clearly required.

\section{Plasmalemma diffusion microkinetic theory of the duration of action of beta $\mathbf{2}_{2}$-adrenoceptor agonists}

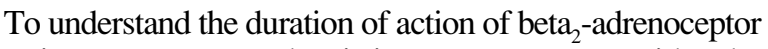
agonists, we propose that it is necessary to consider the plasmalemma diffusion microkinetics of these drugs, i.e. what happens to beta ${ }_{2}$-adrenoceptor agonists in the cell membrane lipid bilayer (plasmalemma) and in the aqueous biophase closest to the active site of the beta-adrenoceptor. When a beta ${ }_{2}$-adrenoceptor agonist is inhaled, surprisingly high topical concentrations are achieved in the periciliary fluid of the bronchi. KERREBIJN [39], basing his estimates on earlier work, has suggested that a single inhalation of terbutaline will lead to topical concentration of up to 100 umnol. $l^{-1}$ in the major bronchi $[39,40]$. Correcting for differences in the inhaled dose, it could be anticipated that formoterol and salmeterol would achieve instantaneous topical concentrations at least as high as $1 \mu \mathrm{mol} \cdot l^{-1}$ in the main bronchi. This represents a substantial bulk concentration, which moves efficiently across the epithelium and into the lamina propria as the drug diffuses towards airway smooth muscle. This bulk effect after inhalation may be essential for long duration, since formoterol is not long-acting when an equieffective bronchodilator dose is administered orally to patients [41]. It is at this point, as molecules of agonist approach the airway smooth muscle cell membrane, that we propose that the physicochemical properties of formoterol and salmeterol become the principal determinants of their duration of action.

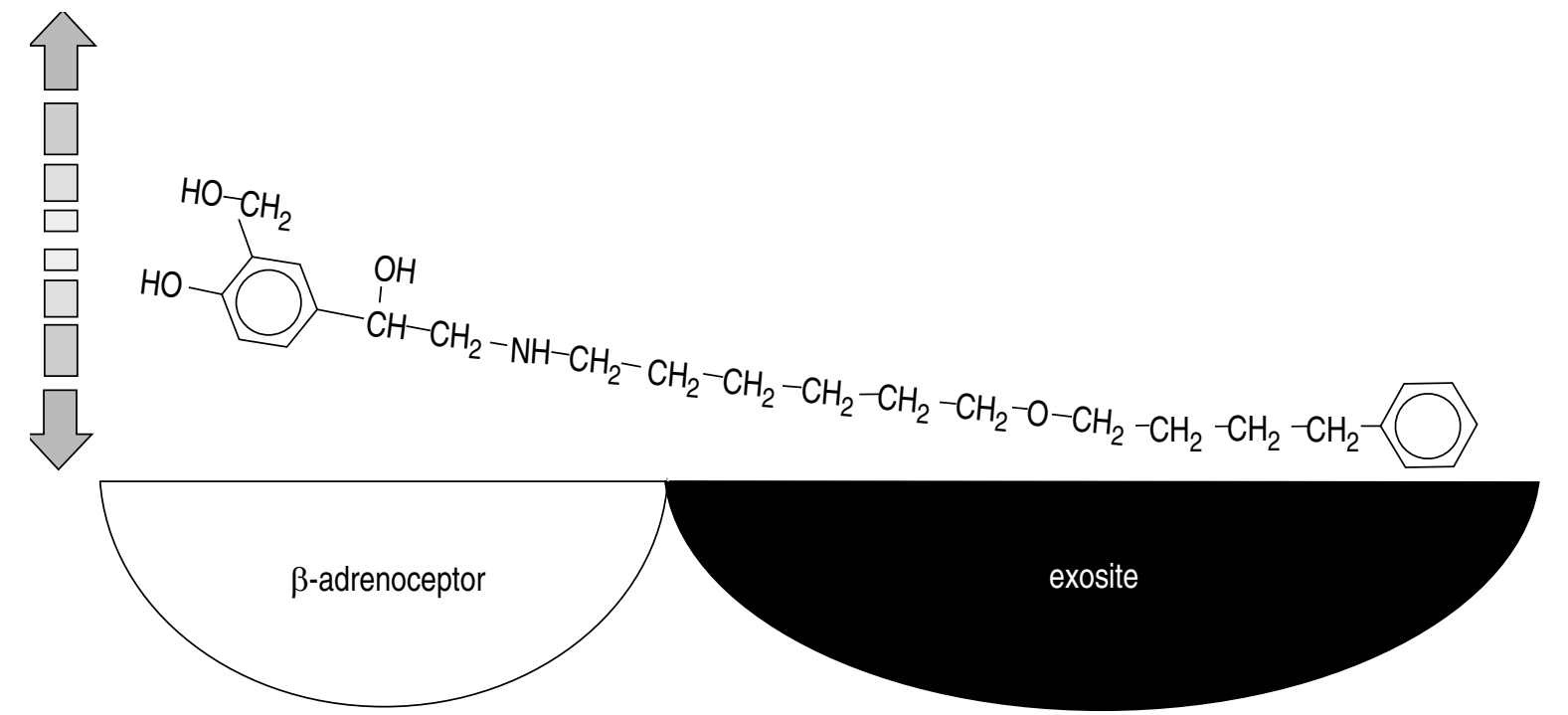

Fig. 4. - The exosite model proposed by Johnson et al. [13] to explain the duration and "reassertion" behaviour of salmeterol. The long aliphatic side-chain of salmeterol is shown binding to a structure distinct from the beta ${ }_{2}$-adrenoceptor (exosite or exoceptor) allowing in the active saligenin

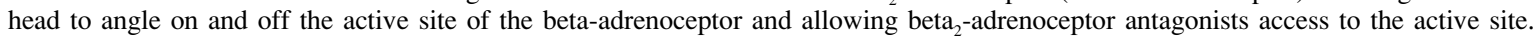


Aqueous biophase
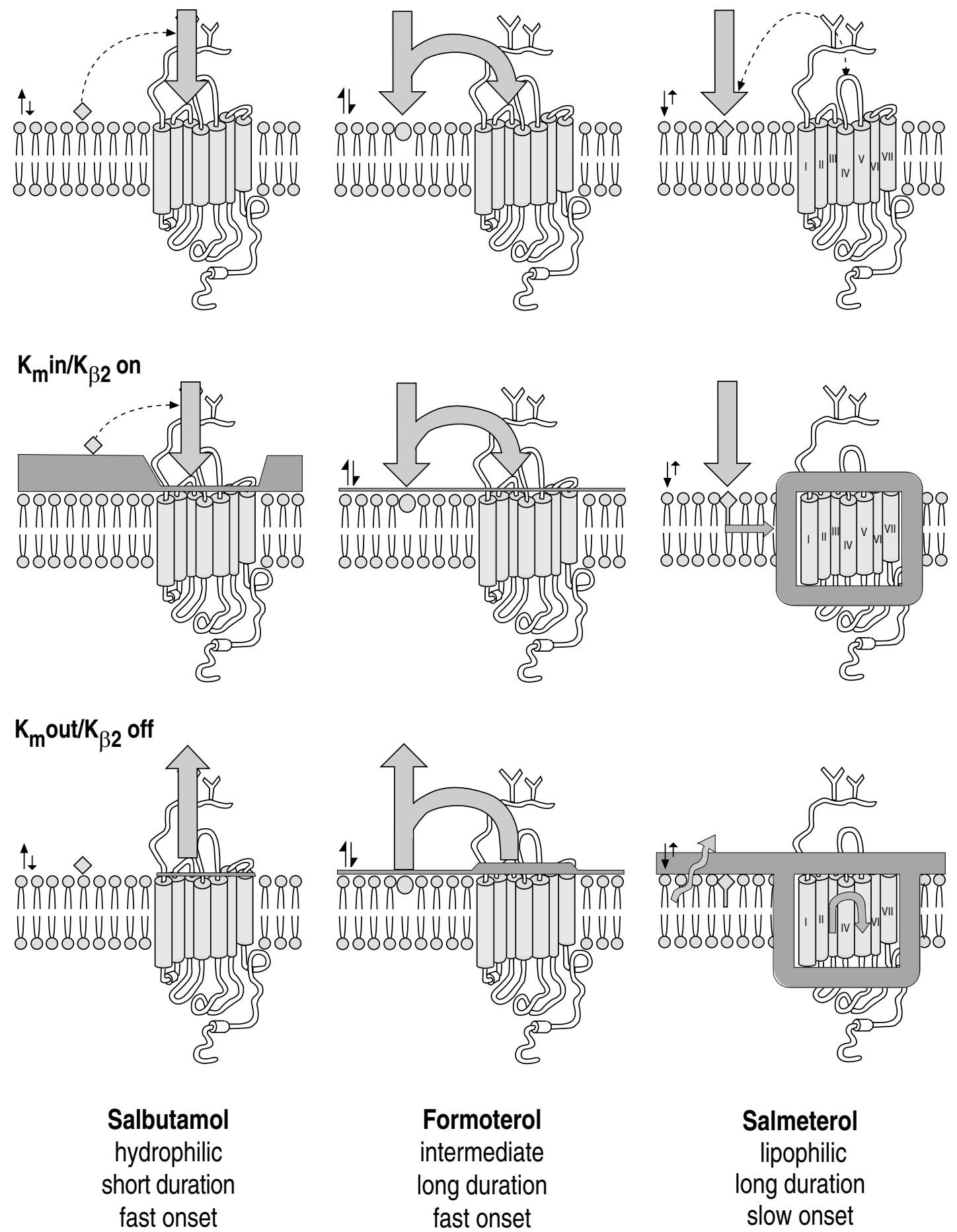

Formoterol
intermediate
long duration
fast onset

$$
\begin{aligned}
& \text { Salmeterol } \\
& \text { lipophilic } \\
& \text { long duration } \\
& \text { slow onset }
\end{aligned}
$$

Fig. 5. - Diffusion microkinetic model. The top panel is an overview of the model which explains duration and reassertion in relation to interactions of salbutamol (left), formoterol (middle) and salmeterol (right) with lipid membranes adjacent to the beta ${ }_{2}$-adrenoceptor. The small arrows at the left of each panel show the drug-lipid equilibrium position. The large shaded arrows show the major movement of drug. During drug association with the receptor (middle panel) the interaction of salbutamol with membrane lipid $\left(\mathrm{K}_{\mathrm{m}}\right.$ in) in very energetically unfavourable (dark shaded barrier) due to its high hydrophilicity and salbutamol associates with the receptor directly ( $\mathrm{K}_{\rho_{2}}$ on) from the aqueous biophase [18]. Therefore, salbutamol exhibits rapid onset, but the drug diffuses from tissues rapidly causing short duration of effect. The association of formoterol with both receptor and lipid is relatively thermodynamically favourable, allowing fast onset $[11,42]$. Formoterol is retained in the lipid to be released over an extended period, continually activating the $\beta$-adrenoceptor. Salmeterol associates predominantly with lipid, and its interaction with the $\beta$-adrenoceptor is proposed to be energetically unfavourable causing slow onset of action [18]. In the lower panel, the dissociation of salbutamol and formoterol from the $\beta$-adrenoceptor is not impeded $\left(\mathrm{K}_{\beta 2} \mathrm{off}\right)$, although the affinity of formoterol for the $\beta$-adrenoceptor is higher than that of salbutamol [11]. Formoterol is retained with moderate affinity by lipid $\left(\mathrm{K}_{\mathrm{m}}\right.$ out $)$ [42]. Salmeterol may slowly form a stable complex with the $\beta$-adrenoceptor, but is also avidly retained by lipid, accounting for slow onset but long duration [18]. 
Figure 5 shows a schematic representation of the plasmalemma diffusion microkinetic theory of duration of action of beta ${ }_{2}$-adrenoceptor agonists. The essential feature of the model is that the plasmalemma lipid bilayer of airway smooth muscle acts as a depot for beta ${ }_{2}-$ adrenoceptor agonists with moderate to high lipophilicity. Beta $_{2}$-adrenoceptor agonists, once having partitioned into the bilayer, remain available to interact with the beta ${ }_{2}^{-}$ adrenoceptor active site. This model appears at first to be inconsistent with traditional views of a ligand approaching the receptor only via the aqueous biophase and of the plasmalemma as an inert substratum for the receptor. In fact, the balance of evidence currently indicates that the membrane itself is a major determinant of the nature of agonism at the beta-adrenoceptor for lipophilic compounds. Aliphatic amines appear to have a natural affinity for partitioning into lung tissue [43, 44], but the molecular basis of the relationship between membrane affinity and duration has not previously been explained.

As indicated in figure 5, in the case of hydrophilic drugs, such as salbutamol (very low solubility in lipid), the partition equilibrium is strongly in favour of the extracellular aqueous compartment. Salbutamol does not partition into the bilayer [20], and is readily removed from the biophase by diffusion into the microcirculation in vivo or by wash-out with fresh buffer in vitro. As such, the onset of effect is rapid, since the molecule can rapidly diffuse to the active site of the receptor, but no persistent relaxation of airway smooth muscle occurs (fig. 3).

In the case of formoterol, which is moderately lipophilic, the partition equilibrium allows the molecule to enter the plasmalemma and to be retained. Concurrently, sufficient drug is available in the aqueous biophase to allow immediate interaction with the active site of the receptor, accounting for the rapid onset of bronchodilation observed clinically. Subsequently, small amounts of formoterol leach out from the plasmalemma and become available for activation

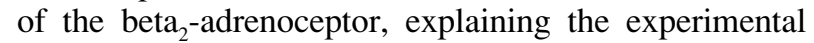
observation of persistent relaxation of airway smooth muscle after wash-out. It should be noted that as little as $30 \%$ of maximal contraction is sufficient to profoundly increase airway resistance in vivo [45]. By analogy, very little muscle length increase is likely to be required to relieve airflow limitation in vivo, suggesting that even small amounts of a potent drug released over time can cause effective bronchodilation (the threshold concentration for relaxation of human airway smooth muscle by formoterol is less than $0.10 \mathrm{nmol} \cdot l^{-1}$ [9], i.e. approximately four orders of magnitude lower than the possible instantaneous topical concentration achieved in major bronchi). This model also explains the reassertion effect after betablockade, since a hydrophilic beta-antagonist, such as sotalol, would compete with formoterol diffusing from the membrane for the beta ${ }_{2}$-adrenoceptor active site according to the law of mass action, but sotalol would wash-out from the tissue readily, whereas formoterol would tend to be retained for a longer period. The partitioning interaction of formoterol into the outer lipid bilayer has recently been demonstrated [42].

For highly lipophilic drugs, such as salmeterol, the partition equilibrium is very much in favour of the plasmalemma lipid bilayer. This partitioning behaviour has been unequivocally demonstrated by the studies of RHOES and co-workers [19]. Using cholesterol and dioleoylphosphatidylcholine as artificial membrane lipid components reconstituted as uni- or multi-lamella liposomes, ${ }^{3} \mathrm{H}$-labelled salmeterol was found to partition into the lipid extremely rapidly $(<1 \mathrm{~min})$ and completely $\left(\mathrm{Kp}_{(\mathrm{mem})}\right.$ 22,500 , compared to salbutamol, $\mathrm{Kp}_{(\mathrm{mem})}<4$ ) but to diffuse from the lipid only slowly (half-life (T1/2) approximately $25 \mathrm{~min}$ at $25^{\circ}$ ). Salmeterol enters only the outer layer of uni-lamella liposomes and does not cross into underlying lipid layers of multi-lamella liposomes to any appreciable extent, implying that salmeterol maintains a highly specific orientation in the outermost leaf of the cell membrane [20]. Neutron diffraction studies, to determine the absolute orientation of salmeterol in the outer lipid bilayer, indicate that salmeterol assumes an orientation analogous to the phospholipids themselves, with its saligenin head in the plane of the phosphate groups and its aliphatic tail extending perpendicularly to the membrane aligned with neighbouring phospholipid groups [46]. Since salmeterol was found to be present in a ratio of one molecule in the aqueous phase to every 22,500 molecules in the lipid membrane at equilibrium, it would therefore be expected that little active salmeterol substance would be present in the aqueous biophase shortly after inhalation. It is actually likely that the majority of salmeterol which activates beta ${ }_{2}$-adrenoceptor, diffuses laterally between the alpha-helices into the beta $_{2}$-adrenoceptor via the membrane lipid bilayer, and never approaches the active site from the extracellular aqueous biophase [46, 47]. A potential intercalation site between helices 4 and 5 of the

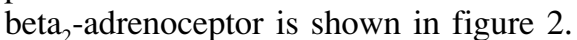

Binding of adrenoceptor agonists, but not antagonists, to adrenoceptors is an exothermic process, i.e. there is an energy barrier that must be overcome [48, 49]. Since salmeterol partitions into membranes in less than one minute, and lateral diffusion of lipids in membranes is very rapid (up to $2 \mu \mathrm{m} \cdot \mathrm{s}^{-1}$ compared to an average airway smooth muscle cell length of approximately $50 \mu \mathrm{m})[20$, $50]$, the slower onset of bronchodilation observed clinically after inhalation of salmeterol, or in vitro $[15,35]$, may be due to the receptor interaction being thermodynamically unfavourable when the agonist approaches the receptor via the lipid membrane (fig. 5). The lack of effect of removing the epithelium on in vitro relaxation time precludes retarded penetration through the epithelium alone as a determinant of slow onset [51].

Very recent computer models of the interaction between salmeterol and the beta $_{2}$-adrenoceptor point to three possible drug receptor interactions. Each possibility assumes that the saligenin head binds to the active core but the lipophilic tail has different orientation in each case: 1) the tail points outward from the receptor into the extracellular space, 2) the tail points down into the receptor towards Asp 79; and 3) the tail remains in the lipid bilayer, while the head enters the receptor [29]. There would be two possible modes of interaction between salmeterol and the beta ${ }_{2}$-adrenoceptor predicted by the diffusion microkinetic model. In the first case, it is physically possible that the pharmacologically inactive 
a)
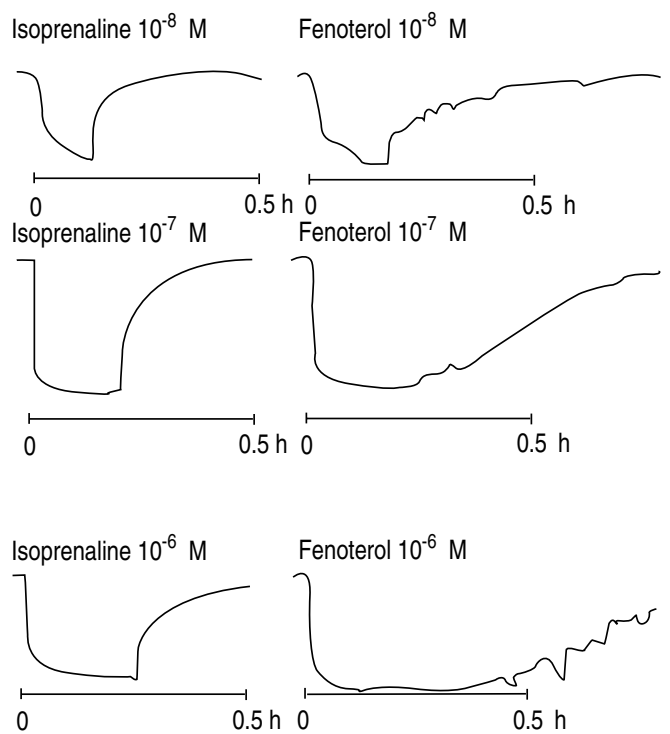

Formoterol $10^{-9} \mathrm{M}$

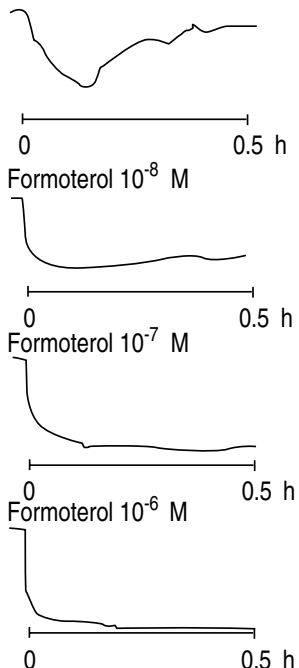

b)

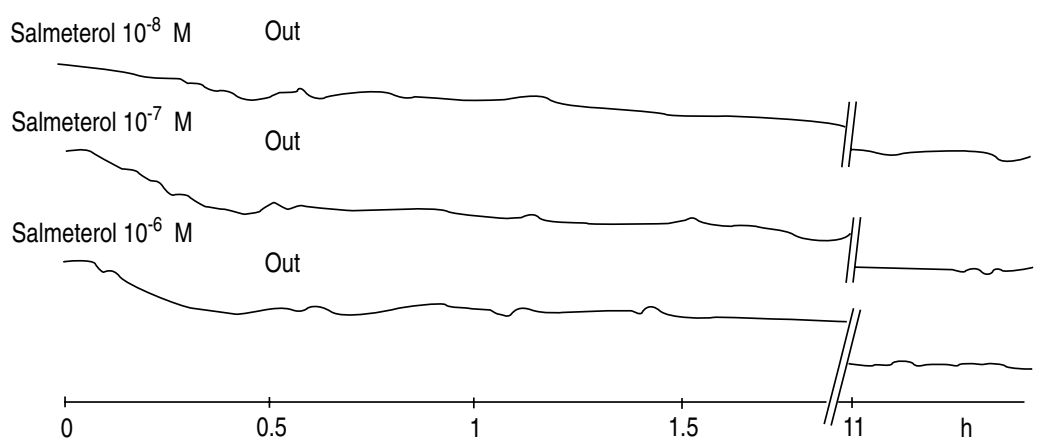

c)

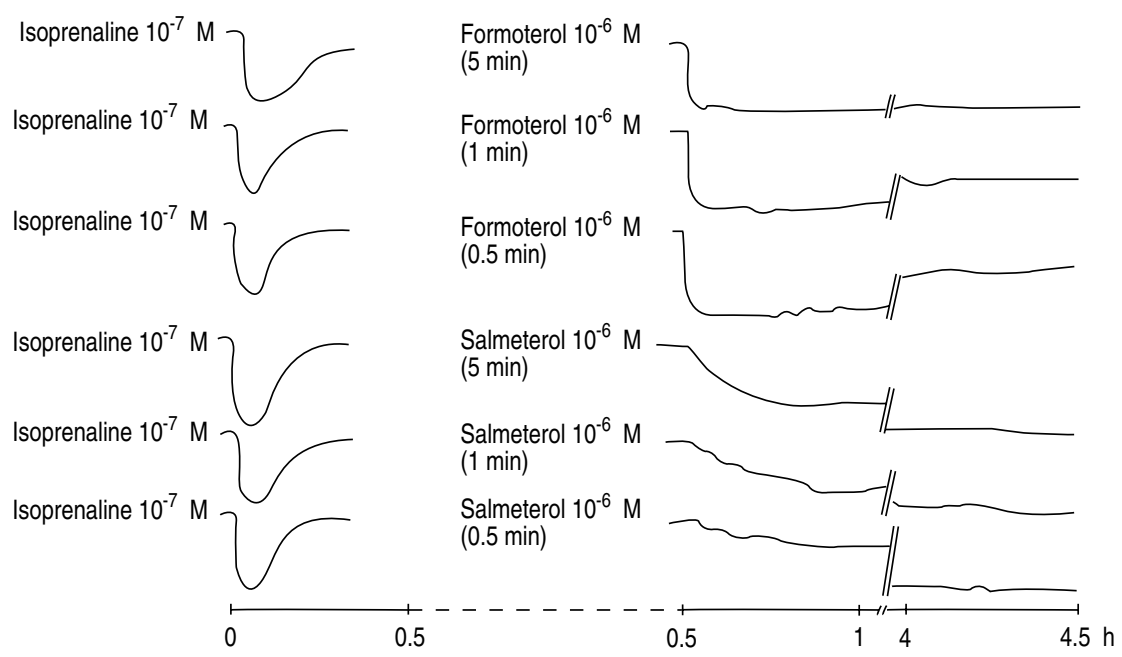

Fig. 6. - Relaxation of human airway smooth muscle by $\beta$-adrenoceptor agonists. a) Shows original recordings from continually superfused human bronchi in vitro exposed to superfusions with $\beta$-adrenoceptor agonists at the indicated concentrations. The traces demonstrate that for isoprenaline, fenoterol and formoterol onset of relaxation is rapid and concentration dependent. At the conclusion of drug superfusion, isoprenaline-induced relaxation is rapidly lost, higher concentrations of fenoterol, and particularly of formoterol, produce sustained relaxations and in all cases the rate of loss of relaxation is lower for higher drug concentrations. In the case of formoterol, little loss of relaxation is observed at concentrations between $10^{-8}$ to $10^{-6} \mathrm{M}$ (i.e. $10 \mathrm{nmol} \cdot l^{-1}$ to $1 \mu \mathrm{mol} \cdot l^{-1}$. b) Results obtained with salmeterol. In contrast, the onset of salmeterol-induced relaxation is always slow but increases somewhat with increased concentration. At the conclusion of drug superfusion the relaxation is not lost but continues to increase at a very slow rate until a maximal response, which is independent of initial concentration over the tested concentration range, is achieved up to $11 \mathrm{~h}$ later. c) Illustrates that for isoprenaline and formoterol the length of time that drug is superfused over the tissues determines both the rate of onset and duration of effect. In the case of salmeterol, the rate of onset is related to duration of administration but the maximal effect in independent of contact time. All recordings were made from human bronchioles of 2-5 $\mathrm{mm}$ internal diameter, under spontaneous tone as described previously [55, 56]. 
tail of salmeterol remains anchored in the outer leaf of the lipid bilayer, whilst the saligenin head intercalates between the alpha-helices of the receptor to reach the active site. This is supported by modelling studies, since the space between adjacent alpha-helices is wide enough to accommodate the lipophilic tail but the receptor would have to distort to allow the saligenin head access to the active site [29]. Such distortion of adjacent alpha-helices is energetically possible [52]. In this case, "reassertion" would be explained by either lateral shuffle of salmeterol to and from the active site of the receptor into the lipid bilayer or displacement of the active head inside the

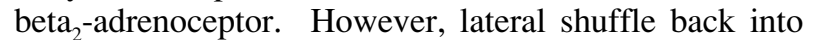
the lipid bilayer is not consistent with binding studies which suggest that salmeterol is not displaced from the receptor and is not consistent with some computer models of salmeterol-receptor interactions [16, 29, 32, 37]. This suggests a second case, in which salmeterol binds, essentially irreversibly, inside the beta ${ }_{2}$-adrenoceptor. "Reassertion" would then be due to an unusual dual occupancy of the binding pocket by both antagonist and agonist. This would require displacement of the active head inside the beta ${ }_{2}$-adrenoceptor, and is feasible since the amino acid residues within the ligand binding core, which are thought to bind antagonists and agonists, are not identical (fig. 2) [49, 53, 54]

The diffusion microkinetic theory also makes a number of testable predictions, such as the likelihood that a true concentration-response relationship for airway smooth muscle relaxation does not occur with salmeterol. In this case, a minute concentration of salmeterol, in which only a small number of molecules partition strongly into the membrane bilayer, would be expected to cause the same maximal effect as a much larger concentration of salmeterol if the relaxant response was followed for a sufficiently long observation period. In human isolated airways the duration of action of beta ${ }_{2}$-adrenoceptor agonists depends on the concentration of drug at the smooth muscle site (fig. 6). Salmeterol behaves differently in this experimental system. Increasing the concentration of salmeterol influences the time of onset of relaxation but does not substantially influence the magnitude of the response, provided a sufficiently long time is allowed to develop full relaxation (fig. 6). Figure 6c illustrates another important difference between formoterol and salmeterol. The duration of action of formoterol, and other beta ${ }_{2}-$ adrenoceptor agonists, in superfused isolated airways in vitro depends on the contact time of agonist administration. This difference cannot be demonstrated with salmeterol. Increasing the contact time of drug administration will influence the speed of onset but not the maximal effect or its duration of action.

The reason for the lack of true concentration-response relationship for salmeterol may be simple. Salmeterol partitions into the membrane, where it is essentially retained with little loss [20]. The statistical probability of a molecule of salmeterol interacting with the sparse population of beta $_{2}$-adrenoceptors is low and, if salmeterol were to diffuse laterally into the receptor between the alpha-helices, the interaction is likely to be energetically unfavourable. However, molecules of salmeterol will eventually enter the beta-adrenoceptor and be retained, activating the transduction system and leading to a cumulative, very slow onset relaxation. The effect of an increased concentration of salmeterol is not to cause a true concentration-response effect, since an equilibrium between the aqueous biophase and receptor is never achieved, but rather to increase the statistical probability of occurrence of an energetically unfavourable salmeterolreceptor combination event via the lipid bilayer. This predicted behaviour is clearly shown in figures $6 \mathrm{a}-\mathrm{c}$.

The diffusion microkinetic theory applies equally to the behaviour of beta-adrenoceptor antagonists. Propranolol, for example has been clearly demonstrated to partition in membrane bilayers and adopt a specific location, approximately $10 \AA$ into the membrane just under the phospholipid head groups, as detected by neutron diffraction. This property has also been observed for timolol which, unlike propranolol, is not formally charged at physiological $\mathrm{pH}[18,57,58]$. The diffusion microkinetic model would predict that antagonists interacting with membranes in airway smooth muscle tissue pre-relaxed by a beta ${ }_{2}$-adrenoceptor agonist would assert their antagonism at a rate broadly related to their lipophilicities. Such a rank order of behaviour has already been demonstrated for the time needed to antagonize salmeterolinduced relaxation of guinea-pig airway smooth muscle: the rank order is propranolol > ICI 118,551 > timolol > sotalol $>$ atenolol $[33,34]$. This order is comparable to the rank order of lipophilicity of these drugs [18, 57-60].

The diffusion microkinetic theory, presented here, has the advantages that it explains the major experimental observations for beta ${ }_{2}$-adrenoceptor agonists of different molecular structures, including the rate of onset and reassertion of smooth muscle relaxation. In addition, the theory also explains the clinically observed anomaly that the plasma concentrations of inhaled beta $_{2}$-adrenoceptor agonists do not necessarily correlate with time course of clinical bronchodilation [59]. Furthermore, the hypothesis is consistent with the major known properties of the longacting beta ${ }_{2}$-adrenoceptor agonists. The diffusion microkinetic model provides a reasonable and testable hypothesis based on experimental data to explain the duration and "reassertion" behaviour of formoterol and salmeterol, and should help to unravel the puzzling behaviour of these new and intriguing molecules.

Acknowledgements: JEPPSSON et al. [15] were first to discuss the relationship between the octanol-water partition coefficient

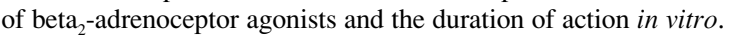
The first proposal that interaction with lipid membranes may relate to "reassertion" was made by LÖFDAHL [35]. Herbette and Rhodes demonstrated membrane partition of propranolol in 1988. Their subsequent work [20] in collaboration with Newton (Head of Chemistry, Glaxo, UK), has proved that rapid membrane interactions occur with salmeterol. The authors are most grateful for information provided by Rhodes and Newton regarding their studies on salmeterol. The authors are also grateful to ADVENIER et al. [9] (Paris, France, for access to work "in press" on responses of human bronchi to salmeterol and formoterol, to N. Cohen (Basel, Switzerland) for molecular modelling studies of salmeterol and formoterol and, to I. Drewett for comments on the manuscript. A preliminary account of the diffusion microkinetic hypothesis was represented in lecture form by G.P.A. in 1991, and subsequently published in outline [47]. 


\section{References}

1. Maesen FPV, Smeets JJ, Gubblemans HHL, Zveers PMGA. Bronchodilator effects of inhaled formoterol vs salbutamol over 12 hours. Chest 1990; 97: 590-594.

2. Ramsdale EH, Otis J, Kline PA, Gontovnick LS, Hargreave FE, O'Byrne PM. Prolonged protection from methacholineinduced bronchoconstriction by the inhaled $\beta$-agonist formoterol. Am Rev Respir Dis 1991; 143: 998-1001.

3. Ullman A, Svedmyr N. Salmeterol, a new long-acting inhaled $\beta_{2}$-adrenoceptor agonist: comparison with salbutamol in asthmatic patients. Thorax 1990; 43: 674-678.

4. Beach JR, Young CL, Stenton SC, Avery AJ, Walters $\mathrm{EH}$, Hendrick DJ. A comparison of the speeds of action of salmeterol and salbutamol in reversing methacholineinduced bronchoconstriction. Pulm Pharmacol 1993; 5: 133-135.

5. Rabe, KF, Jörres R, Nowak D, Behr N, Magnussen H. Comparison of the effects of salmeterol and formoterol on airway tone and responsiveness over 24 hours in bronchial asthma. Am Rev Respir Dis 1993; 147: 1436-1441.

6. Hekking PRM, Maesen F, Greefhorst A, Prins J, Tan Y. Efficacy and tolerability of inhaled formoterol compared with inhaled salbutamol over three months. In: Barnes PJ, Matthys H, eds. Formoterol a new generation beta agonist. Toronto, Hogrefe and Huber Publishers, 1990; pp. $40-44$.

7. Pauwels R. Rate of onset and duration of action of beta agonists: comparison of inhaled formoterol with salbutamol. In: Barnes PJ, Matthys $\mathrm{H}$, eds. Formoterol a new generation beta - -agonist. Toronto, Hogrefe and Huber Publishers, 1990; pp. 35-39.

8. Ullman A, Hedner J, Svedmyr N. Inhaled salmeterol and salbutamol in asthmatic patients. An evaluation of asthma symptoms and possible development of tachyphylaxis. Am Rev Respir Dis 1990; 142: 571-575.

9. Advenier C, Zhang Y, Naline E, Marion N, Anderson GP, Grandordy B. Relaxant effects and long duration of action of formoterol on the human isolated bronchus. 1993; (In press).

10. Ball DI, Brittain RT, Coleman RA, et al. Salmeterol, a novel, long-acting, $\beta$-adrenoceptor agonist: characterisation of pharmacological activity in vitro and in vivo. $\mathrm{Br} \mathrm{J}$ Pharmacol 1991; 104: 665-671.

11. Decker N, Quennedey MC, Rouot B, Schwartz J, Velley J. Effects of $N$-aralkyl substitution of $\beta$-agonists on $\alpha$ and $\beta$-adrenoceptor subtypes: pharmacological studies and binding assays. J Pharm Pharmacol 1982; 34: 107-112.

12. Lemoine H, Overlack C, Worth H, Reinhardt D. Increased muscarinic prestimulation of guinea-pig tracheal strips decreases potency and intrinsic activity of synthetic beta $2_{2}^{-}$ sympathomimetics. Comparison of relaxation with receptor binding and adenylate cyclase stimulation. Naunyn Sch Arch Pharmacol 1991; 343: R98.

13. Johnson M. Salmeterol: a novel drug for the treatment of asthma. In: Anderson GP, Morley J, eds. New Drugs for Asthma. Basel, Birkhauser Verlag, 1992; pp. 7995.

14. Lindén A, Bergendal A, Ullman A, Skoogh B-E, Löfdahl C-G. Long- and short-acting $\beta_{2}$-agonists in the isolated guinea-pig trachea: efficacy, potency and functional antagonism. Eur Respir J 1991; 4(Suppl. 14): P137.

15. Jeppsson A-B, Löfdahl C-G, Waldeck B, Widmark E. On the predictive value of experiments in vitro in the evaluation of the effect during of bronchodilator drugs for local administration. Pulm Pharmacol 1989; 2: 81-85.
16. Brittain RT. Approaches to a long-acting selective $\beta_{2}-$ adrenoceptor stimulant. Lung 1990; 168(Suppl.): 142-153.

17. Mohamadi F, Richards NGJ, Guida WC, et al. Macromodel. J Comput Chem 1990; 11: 440.

18. Herbette LG, Chester DW, Rhodes DG. Structural analysis of drug molecule interactions in biological membranes. Biophys J 1986; 49: 91-94.

19. Mason RP, Rhodes DG, Herbette LG. Re-evaluating equilibrium and kinetic binding parameters for lipophilic drugs based on a structural model of drug interactions with biological membranes. J Med Chem 1991; 34: 869-877.

20. Rhodes DG, Newton R, Butler R, Herbette L. Equilibrium and kinetic studies of the interactions of salmeterol with membrane bilayers. Mol Pharmacol 1992; 42: 596602.

21. Fraser CM, Venter JC. Beta-adrenergic receptors. Relationship of primary structure, receptor function, and regulation. Am Rev Respir Dis 1990; 141: S22-S30.

22. Tota MR, Candelore MR, Dixon RAF, Strader CD. Biophysical and genetic analysis of the ligand binding site of the beta-adrenoceptor. Trend Pharmacol Sci 1991; 12: 4-6.

23. Dixon RA, Sigal IS, Rands E, et al. Ligand binding to the $\beta$-adrenergic receptor involves its rhodopsin-like core. Nature 1987; 326: 73-77.

24. Hibert MF, Trump-Kallmeyer S, Bruinvels A. Threedimensional models of neurotransmitter G-binding protein coupled receptors. Mol Pharmacol 1991; 40: 8-15.

25. Henderson R, Unwin PNT. Three-dimensional model of purple membrane obtained by electron microscopy. Nature 1975; 257: 28-32.

26. Henderson R, Baldwin JM, Ceska TA, Zemlin F, Beckmann E, Downing KH. Model for the structure of bacteriorhodopsin based on high resolution electron cryomicroscopy. J Mol Biol 1990; 213: 899-929.

27. Dixon RA, Kobila BK, Strader DJ, et al. Cloning of the gene and cDNA for mammalian $\beta$-adrenoceptor and homology with rhodopsin. Nature 1986; 321: 75-79.

28. Applebury ML, Hargreave PA. Molecular biology of the visual pigments. Vision Res 1986; 26: 1881-1895.

29. Lewell XQ. A model of the adrenergic beta 2 -receptor and binding sites for agonists and antagonists. Drug Design Discovery 1992; 9: 29-48.

30. Lindén A, Bergendal A, Ullman A, Skoogh B-E, Löfdahl C-G. High concentration of formoterol and salmeterol in the isolated guinea-pig trachea: reassertion of smooth muscle relaxation after beta blockade followed by washout. Am Rev Respir Dis 1990; 143 4(2): A749.

31. Bradshaw J, Brittain RT, Coleman RA, et al. The design of salmeterol, a long-acting selective $\beta_{2}$-adrenoceptor agonist. Br J Pharmacol 1987; 92: 509P.

32. Coleman RA, Johnson M, Nials AT, Sumner MJ. Salmeterol but not formoterol persists at beta ${ }_{2}$-adrenoceptors in vitro. Br J Pharmacol 1990; 99(Suppl.): 121P.

33. Nials AT, Coleman RA. The interaction between salmeterol and beta-adrenoceptor blocking drugs on guinea-pig isolated trachea. Br J Pharmacol 1988; 95(Suppl.): 540P.

34. Nials AT, Summer MJ, Johnson M, Coleman RA. Investigations into the factors determining the duration of action of the $\beta_{2}$-adrenoceptor agonist, salmeterol. Br J Pharmacol 1993; 108: 507-515.

35. Löfdahl C-G. Basic pharmacology of new long-acting sympathomimetics. Lung 1990; 168(Suppl.):18-21.

36. O'Donnell SR. Selectivity of clenbuterol (NAB365) in guinea-pig isolated tissues containing $\beta$-adrenoceptors. Arch Int Pharmacodyn Ther 1976; 224: 190-198. 
37. Jack D. A way of looking at agonism and antagonism: lessons from salbutamol, salmeterol and other $\beta$-adrenoceptor agonists. Br J Clin Pharmacol 1991; 31: 501-514.

38. Nials AT, Butchers PR, Coleman RA, Johnson M, Vardey CJ. Salmeterol and formoterol: are they both long-acting beta ${ }_{2}$-adrenoceptor agonists. Br J Pharmacol 1990; 99(Suppl.): 120P.

39. Kerrebijn KF. Long-term drug treatment of asthma in children. Lung 1990; 168(Suppl): 142-153.

40. Newman SP. Therapeutic Aerosols. In: SW Clarke, D Pavia, eds. Aerosols and the Lung. London, Butterworths, 1984; pp. 197-224.

41. Löfdahl C-G, Svedmyr N. Formoterol fumarate, a new beta-adrenoceptor agonist. Acute studies of selectivity and duration after inhaled and aerosol administration. Allergy 1989; 44: 264-271.

42. Jaekel K, John E, Anderson GP. Comparative biophysical analysis of interactions between formoterol, salbutamol or salmeterol and lipid membranes (Abstract). European Respiratory Society Proceedings, 1993; (In press).

43. Fowler JS, Gallagher BM, MacGregor RR, Wolf AP. Carbon-11 labelled aliphatic amines in lung uptake and metabolic studies: potential for dynamic measurements. J Pharmacol Exp Ther 1977; 198: 133-145.

44. Yoshida H, Okumura K, Hori R. Subcellular distribution of basic drugs accumulated in the isolated perfused lung. Pharmacol Res 1987; 4: 50-53.

45. Moreno RH, Hogg JC, Paré PD. Mechanics of airway narrowing. Am Rev Respir Dis 1986; 133: 11711180.

46. Johnson M, Butchers PR, Coleman RA, et al. The pharmocology of salmeterol. Life Sci 1993, 52: 2131-2144.

47. Anderson GP. Molecular pharmacology of formoterol. In: Holgate ST ed. Formoterol: Fast and Long-lasting Bronchodilatation. London, Royal Society of Medicine International Congress and Symposium Series. 1992; pp. 3-11.

48. Contreras ML, Wolfe BB, Molinoff PB. Thermodynamic properties of agonist interactions with the beta-adrenergic receptor-coupled adenylate cyclase system 1 . High and low affinity states of agonist to membrane bound betaadrenergic receptors. J Pharmacol Exp Ther 1986; 237: 154-163.

49. Jasper JR, Insel PA. Evolving concepts of partial agonism. The $\beta$-adrenergic receptor as a paradigm. Biochem Pharmacol 1992; 43: 119-130.
50. Stryer L. Introduction to biological membranes. In: Stryer L, ed. Biochemistry (2nd edn), San Francisco, WH Freeman and Co., 1981; pp. 205-230.

51. Ullman A, Bergendal A, Lindén A, Waldeck B, Skoogh B-E, Löfdahl C-G. Onset of action and duration of effect of formoterol and salmeterol compared to salbutamol in isolated guinea-pig trachea with and without epithelium. Allergy 1992; (In press).

52. Cramer WA, Engelman DM, Von Heijne G, Rees DC. Forces involved in the assembly and stabilization of membrane proteins. FASEB J 1992; 6: 3397-3402.

53. Frielle T, Daniel KW, Caron MG, Lefkowitz RJ. Structural basis of $\beta$-adrenergic sub-type specificity studied with chimeric $\beta 1 / \beta 2$-adrenergic receptors. Proc Natl Acad Sci (USA) 1988; 85: 9494-9498.

54. Kobilka BK, Kobilka TS, Daniel K, Regan JW, Caron MG, Lefkowitz RJ. Chimeric $\alpha_{2}-, \beta_{2}$-adrenergic receptors: delineation of domains involved in effector coupling and ligand binding specificity. Science 1988; 240: 1310-1316.

55. Nials AT, Coleman RA, Johnson M, Magnussen H, Rabe $\mathrm{KF}$, Vardey CJ. Effects of $\beta$-adrenoceptor agonists in human bronchial smooth muscle. Br J Pharmacol 1993; (In press).

56. Rabe KF, Bodtke K, Liebig S, Magnussen H. Modulation of inherent tone of human airways in vitro. Am Rev Respir Dis 1992: 145: A378.

57. Herbette LG, Katz AM, Sturtevant JM. Comparisons of the interactions of propranolol and timolol with model and biological membrane systems. Mol Pharmacol 1983; 24: 259-269.

58. Herbette LG, Trumbore M, Chester DW, Katz AM. Possible molecular basis for the pharmacokinetics and pharmacodynamics of three membrane-active drugs: propranolol, nimodipine and amiodarone. J Mol Cell Cardiol 1988; 20: 373-378.

59. Jenne JW, Ahrens RC. Pharmacokinetics of beta-adrenergic compounds. In: Jenne JW, Murphy S, eds. Drug Therapy for Asthma: Research and Clinical Practice. Lung Biology in Health and Disease. Vol. 31. New York, Marcel Dekker, 1987; pp. 213-258.

60. Hellenbrecht D, Lemmer B, Wiethold G, Grobecker H. Measurement of hydrophobicity, surface activity, local anaesthesia, and myocardial conduction velocity as quantitative parameters of the nonspecific membrane affinity of nine $\beta$-adrenergic blocking agents. Naunyn Sch Arch Pharmacol 1973; 277: 211-226. 